\title{
ÉPOCAS DE PODA NA PRODUÇÃO DE FIGOS VERDES 'ROXO DE VALINHOS' EM SISTEMA ORGÂNICO NA REGIÃO OESTE DO PARANÁ ${ }^{1}$
}

\author{
IDIANA MARINA DALASTRA ${ }^{2}$, RAFAEL PIO ${ }^{3}$, MARCELO ANGELO CAMPAGNOLO ${ }^{4}$, \\ GRACIELA MAIARA DALASTRA ${ }^{5}$, EDVAN ALVES CHAGAS ${ }^{6}$, VANDEIR FRANCISCO GUIMARÃES ${ }^{7}$
}

RESUMO - O objetivo deste trabalho foi verificar o efeito da época de poda sobre o crescimento e a produção da figueira ‘Roxo de Valinhos’, cultivada na região oeste do Paraná, sob sistema orgânico, para a produção de figos-verdes. O delineamento utilizado foi em blocos ao acaso, com quatro blocos e seis tratamentos - épocas de poda: abril, maio, junho, julho, agosto e setembro. Em cada parcela, constituída de três plantas úteis, foram coletados dados no ciclo de produção de 2007/2008. As variáveis fenológicas, comprimento final médio dos ramos, produção por mês (número e massa média de frutos por planta e produtividade estimada, entre os meses de outubro a fevereiro), produção acumulada, produtividade estimada acumulada e massa fresca média dos frutos. Houve diferenças na produção entre as épocas de poda; plantas podadas em julho e agosto apresentaram as maiores produções, escalonadas entre os meses de dezembro a fevereiro, com pico de produção em janeiro.

Termos para Indexação: Ficus carica L., antecipação da produção, época de colheita. fenologia.

\section{PRUNING TIME IN THE PRODUCTION OF 'Roxo de Valinhos’ GREEN FIG IN ORGANIC SISTEM IN THE WEST REGION OF PARANÁ STATE}

\begin{abstract}
The objective of this work was to verify the effect of pruning time on growth and production of the 'Roxo de Valinhos' fig tree fruit grown in the West Paraná region, under organic system, for the production of green figs. The design utilized was randomized blocks with four blocks and six treatments the pruning times: April, May, June, July, August and September. In each plot, made up of three useful plants, data concerning the cropping cycles of 2007/2008 were collected. The variable phenologies, final medium length of the branches, month production (number and medium mass of fruits per plant and estimate productivity, from the months of October to February), accumulated production, estimate accumulated productivity and average fresh mass of the fruits. There were yield differences among pruning times; the July and August pruned plants presented higher yields, from December to February, with production pick in January.
\end{abstract}

Index Terms: Ficus carica L., anticipated production, harvesting time, phenology.

\footnotetext{
${ }^{1}$ (Trabalho 114-08). Recebido em: 17-05-2008. Aceito para publicação em: 03-03-2009.

${ }^{2}$ Eng $^{\circ}$. Agrônoma, M.Sc., Doutoranda do curso de Pós-graduação em Agronomia, Universidade Estadual Paulista-Unesp, Faculdade de Ciências Agronômicas de Botucatu, Departamento de Produção Vegetal. Fazenda Experimental Lageado s/n, 18603970, Botucatu-SP. ididalastra@yahoo.com.br

${ }^{3}$ Eng $^{\circ}$. Agrônomo, D.Sc., Professor Adjunto da Universidade Federal do Paraná - UFPR. Rua dos Funcionários, $\mathrm{n}^{\circ}$ 1540, Juvevê, 80035-050, Curitiba-PR. Bolsista Produtividade em Pesquisa CNPq. Autor para correspondência: rafaelpio@hotmail.com

${ }^{4}$ Biólogo, M.Sc., Doutorando do curso de Pós-graduação em Agronomia, Universidade Estadual do Oeste do Paraná Unioeste. Rua Pernambuco, $\mathrm{n}^{\circ}$ 1777, Caixa Postal 1008, Centro, 85960-000, Marechal Cândido Rondon-PR. Bolsista do CNPq. campa_bio@yahoo.com.br

${ }^{5}$ Acadêmica do curso de Agronomia, Universidade Estadual do Oeste do Paraná - Unioeste. Rua Pernambuco, n 1777, Caixa Postal 1008, Centro, 85960-000, Marechal Cândido Rondon-PR. gradalastra@hotmail.com

${ }^{6}$ Eng $^{0}$. Agrônomo, D.Sc., Pesquisador Científico Embrapa Roraima. Rod. 174, Km 08, Caixa Postal 133, 69301-970, Boa Vista-RR. Bolsista Produtividade em Pesquisa CNPq. echagas@cpafrr.embrapa.br

${ }^{7}$ Eng $^{\circ}$. Agrônomo, D.Sc., Professor Adjunto da Universidade Estadual do Oeste do Paraná - Unioeste. Rua Pernambuco, ${ }^{\circ}$ 1777, Caixa Postal 1008, Centro, 85960-000, Marechal Cândido Rondon-PR. vandeirfg@yahoo.com.br
} 


\section{INTRODUÇÃO}

O Brasil é considerado o maior produtor de figos do Hemisfério Sul, numa área cultivada de aproximadamente 3.020 ha. O País detém a sétima maior produção mundial (26.476 t) e a quinta maior produtividade $\left(8,76 \mathrm{t} \mathrm{ha}^{-1}\right)$, o que aloca o Brasil como um dos maiores produtores e o principal exportador de figos frescos para o mercado egípcio, turco e libanês, maiores consumidores mundiais do fruto (FAO, 2008; IBGE, 2008).

As razões para os bons resultados produtivos e comerciais obtidos no País com a figueira (Ficus carica L.), que se constituiu na atualidade como uma das mais importantes frutíferas de clima temperado cultivada, está estreitamente ligado a sua larga adaptação climática e rusticidade (Pio et al., 2007). Outra razão são os fins de aproveitamento agronômicos dos subprodutos, não incipiente a utilização nobre dos frutos in natura, mas também no aproveitamento das folhas na fabricação de bebidas fermentadas, ramos como propágulos e a extração da ficcina, enzima proteolítica com propriedade hidrolisante da proteína (Alvarenga et al., 2007).

O Estado de São Paulo é o único Estado brasileiro exportador e o maior produtor de figos voltados para a produção de frutos ao natural (IBGE, 2008). Tecnologias e pesquisas foram intensificadas, colocando São Paulo como o maior detentor mundial da produtividade de figos $\left(24,82 \mathrm{t} \mathrm{ha}^{-1}\right)$, maior que a Macedônia, Líbia e Israel, países que detêm as maiores tecnologias na ficicultura (FAO, 2008; IBGE, 2008). Porém, analisando a área de cultivo no Estado, nota-se que houve acentuado decréscimo nos últimos anos. Assim, detectou-se a redução da área cultivada com figos em aproximadamente $21 \%$ nos últimos 13 anos, passando de 487 ha em 1994 para 386 ha cultivados com figos em 2007 (IBGE, 2008). As razões para essa diminuição foram devidas não somente à escassez de mão de obra especializada, exigida principalmente no momento da colheita, mas também pela elevada exploração imobiliária ocorrida no "Circuito das Frutas" paulista (localizado no centrosul do Estado, região de Campinas-SP), pela valorização da terra provocada por loteamentos imobiliários e pela urbanização (Francisco et al., 2008).

Uma alternativa para os ficicultores paulistas e para os demais produtores de outros Estados, principalmente os de Minas Gerais, seria a produção orgânica de figos-verdes voltados para o processamento industrial, buscando-se melhores preços frente à agregação de valores.

Atualmente, vem-se percebendo o aumento do interesse pelos consumidores de produtos produzidos de forma natural, ausentes de resíduos químicos decorrentes da exploração convencional de plantas hortícolas. A fruticultura orgânica ainda se encontra incipiente, o que resulta em oferta muito irregular de produtos nas prateleiras dos supermercados e nas feiras. No entanto, o crescimento do mercado brasileiro para os produtos orgânicos tem sido significativo, estimado em 30\% no ano de 2005, com frutos e hortaliças orgânicas representando $2 \%$ do total comercializado pelas redes de supermercados no País (Agrianual, 2007).

A tendência pela produção de produtos ecologicamente coerentes é forte frente à sociedade, no entanto há falta de informações científicas e técnicas nas adequações do sistema produtivo convencional para o orgânico na maioria das espécies cultivadas, principalmente a figueira.

A figueira no Brasil é conduzida no sistema de podas drásticas (poda de produção), realizada durante o período hibernal das plantas, eliminandose os ramos que vegetaram e produziram no ciclo anterior (pernadas) (Pio et al., 2007). Devido a esse sistema de podas drásticas, as figueiras têm sua estrutura de copa composta de uma haste principal de 40-60 cm de altura, três ramos primários de 15-20 cm de comprimento, de onde se inserem dois ramos secundários de 10-15 cm, totalizando assim seis ramos secundários. Em sistema de produção de figos-verdes destinados à industrialização, as plantas são espaçadas de 1,5 x 2,5 m a 2 x 3 m e são conduzidas doze pernadas produtivas, duas em cada ramo secundário, que são eliminadas no período hibernal (julho a agosto - poda invernal) (Chalfun et al., 2002). No entanto, a época de poda pode variar de maio a novembro, com o objetivo de acelerar ou retardar a época da colheita, respectivamente, conforme as condições climáticas do local e o desenvolvimento da planta (Chalfun et al., 1998).

A planta podada nestes períodos poderá ter a produtividade afetada, podendo, porém, apresentar vantagens econômicas. Santos \& Corrêa (2000) relatam que a poda antecipada na região de ValinhosSP, predispõe a figueira a geadas tardias. Contudo, em regiões de inverno ameno, como é o caso de Lavras, sul do Estado de Minas Gerais, a poda realizada precocemente pode resultar em colheitas antecipadas, possibilitando a oferta de figo na entressafra e proporcionando melhores preços (Norberto et al., 2001).

Para a região oeste do Paraná, caracterizada por apresentar inverno ameno seguido de verão intenso, característico de regiões subtropicais, há carência de estudos no que tange ao sistema de 
condução da figueira, principalmente quanto à época de realização da poda hibernal das plantas e ainda informações pertinentes à produção de figosverdes em sistema orgânico.

O presente trabalho foi realizado com o intuito de verificar a possibilidade do escalonamento da safra de figos-verdes, bem como definir a época ideal de realização da poda, em plantas conduzidas em sistema orgânico.

\section{MATERIAL E MÉTODOS}

O trabalho foi conduzido em um pomar comercial de figueira 'Roxo de Valinhos', com quatro anos de idade, manejado em sistema orgânico, com espaçamento $3 \times 2 \mathrm{~m}$ e plantas conduzidas em sistema de poda drástica, com seis ramos secundários, localizado no município de Quatro Pontes-PR. O local situa-se a $472 \mathrm{~m}$ de altitude nos paralelos de $24^{\circ} 35^{\prime} 42^{\prime \prime}$ latitude sul e 5359'54" longitude oeste. De acordo com a divisão climática do Estado do Paraná, a região oeste está sob influência do tipo climático Cfa - zona subtropical úmida, mata pluvial, com temperatura média máxima anual de $28,5^{\circ} \mathrm{C}$ e mínima de $16,6^{\circ} \mathrm{C}$ (Maack,1981). O solo da área experimental é do tipo Latossolo Vermelho eutroférrico, pertencente ao grande grupo Latossolo (Embrapa, 2006). Antes da implantação do experimento (março de 2007), foram coletadas amostras compostas de solo, na profundidade de 0 $20 \mathrm{~cm}$, na projeção da copa das plantas e analisadas no Laboratório de Química Agrícola e Instrumental, da Universidade Estadual do Oeste do Paraná (Unioeste) Marechal Cândido Rondon-PR (Tabela $1)$.

As podas de produção foram realizadas no primeiro dia dos meses de abril, maio, junho, julho, agosto e setembro. O delineamento estatístico utilizado foi em blocos ao acaso, com seis tratamentos (época de poda), quatro blocos, cinco plantas por parcela, sendo utilizadas as três plantas centrais para as avaliações. No momento de cada poda, foram distribuídos cinco litros de esterco de curral curtido por planta.

$\mathrm{Na}$ operação de poda, foram removidas as brotações produtivas (pernadas) do último ciclo vegetativo, cortando as no ponto de inserção aos ramos secundários, com auxílio de tesoura de poda e pincelando o local podado com pasta bordaleza. A desbrota foi realizada quando as brotações atingiram $10 \mathrm{~cm}$ de comprimento, respeitando-se o crescimento diferenciado de cada época de poda, mantendo-se 12 brotações remanescentes por planta, duas a cada pernada secundária. Durante a condução do experimento, foram realizadas quatro roçagens das plantas invasoras em toda a área experimental, nos meses de abril, julho, outubro e janeiro. No período produtivo, foram realizadas desbrotas periódicas, eliminando-se as brotações laterais. Foram realizadas, também, aplicações de calda bordaleza a $1 \%$, a cada 21 dias, e duas aplicações de esterco de curral curtido (cinco litros por planta, espalhados na projeção da copa), uma em novembro e outra em janeiro. Durante a fase experimental, foram coletadas as temperaturas máximas, mínimas e a precipitação diária, sendo calculada a média mensal (Figura 1). Calculou-se ao final do experimento a quantidade de graus-dia acumulados, de acordo com as fórmulas de Villa Nova et al. (1972) e número de unidades de horas de frio acumuladas nos meses que antecederam cada época de poda (número de horas de frio - NHF, abaixo de $7,2^{\circ} \mathrm{C}$ ), segundo a recomendação de Pedro Jr. et al.(1979), através das fórmulas:

$$
\begin{array}{ll}
\mathrm{GD}=\left(\mathrm{T}_{\text {mín }}-\mathrm{Tb}\right)+\frac{\left(\mathrm{T}_{\text {máx }}-\mathrm{T}_{\text {mín }}\right)}{2} & \text { Quando } \mathrm{T}_{\text {mín }}>\mathrm{Tb} \\
\mathrm{GD}=\frac{\left(\mathrm{T}_{\text {máx }}-\mathrm{Tb}\right)^{2}}{2 \times\left(\mathrm{T}_{\text {máx }}-\mathrm{T}_{\text {mín }}\right)} & \text { Quando } \mathrm{T}_{\text {mín }}<\mathrm{Tb}
\end{array}
$$

Onde: GD = graus-dia; Tmáx. = temperatura máxima diária em ${ }^{\circ} \mathrm{C}$; Tmín. = temperatura mínima diária em ${ }^{\circ} \mathrm{C} ; \mathrm{Tb}=10$ (temperatura base)

NHF $=401,9-21,5 \times$ Tméd mensal.

As variáveis mensuradas foram: variáveis fenológicas (período entre a poda e a desbrota, período entre a desbrota e a primeira colheita e período de safra, em dias), comprimento final médio dos ramos (média de três ramos por planta), produção por mês (número e massa média de frutos por planta e produtividade estimada, entre os meses de outubro e fevereiro), produção acumulada, produtividade estimada acumulada e massa fresca média dos frutos (média de 12 frutos amostrados por mês, calculandose apenas a massa média unitária acumulada por bloco). As colheitas foram realizadas semanalmente, colhendo somente os frutos que apresentavam diâmetro de três centímetros e ostíolo vermelho e inchado.

Os dados foram submetidos à análise de variância, sendo os dados de produções mensais (produção de número e massa de frutos por planta e produtividade estimada) submetidos à análise em parcela subdividida no tempo (mês como parcela principal e época de poda como subparcela) e as médias das variáveis fenológicas, produção e produtividade estimada acumulada, comparadas pelo teste Scott-Knott, a 5\% de probabilidade. 


\section{RESULTADOS E DISCUSSÃO}

Quanto às fenofases da figueira, verificou-se a influência da época de poda no período de desbrota, nas quais, podas concentradas nos meses de setembro e agosto promoveram menor tempo demandado para a operação da desbrota (25 e 30 dias, respectivamente). No entanto, a poda realizada em abril demandou apenas 37 dias para a realização da desbrota, menor tempo em comparação à poda realizada em maio, que demandou 100 dias para a realização dessa operação (Tabela 2 ).

Pelos dados climáticos referentes ao período experimental, no mês de abril, temperaturas elevadas associadas à precipitação de $253 \mathrm{~mm}$ favoreceram o intumescimento das gemas e a sucessiva brotação. A diminuição da temperatura e da intensidade de precipitação nos meses subsequentes (Figura 1) resultou no prolongamento do período de realização da desbrota em maio, junho e julho. A diminuição da temperatura e da precipitação prolongou o tempo para a realização da primeira colheita nas podas precoces, 210 dias para a poda realizada em abril e 90 dias para a poda realizada em maio, a partir da desbrota. Da poda de abril à primeira colheita, demandaram-se 247 dias, e a de maio, 190 dias. Esse tempo prolongado poderia estar relacionado ao número de horas de frio (abaixo de $7,2^{\circ} \mathrm{C}$ ) não acumuladas, para as podas realizadas nesses meses (Tabela 2).

Por ser uma frutífera de clima temperado, a figueira necessita de acúmulo de baixas temperaturas para ocorrer a quebra da dormência das gemas, mesmo sendo considerada uma das menos exigentes em quantidades de horas de frio, próximo a 50 horas (Chalfun et al., 1998). Apesar dessa rusticidade, a saída da dormência e a entrada em produção estão estreitamente correlacionadas às condições climáticas do local de cultivo, motivo pelo qual houve maior período de safra para as podas efetuadas entre os meses de junho e agosto. Mesmo acumulando maior quantidade de graus-dia, podas realizadas precocemente apresentam menor período de safra, possivelmente pela ausência de número de horas de frio acumuladas e pelas condições climáticas do próprio inverno (Tabela 2).

Não há relatos na literatura da descrição fenológicas da vegetação e do período de safra em plantas de figueira podadas em épocas distintas. Tais informações vêm a auxiliar a programação das operações de manejo cultural, principalmente no que tange ao deslocamento e concentração da produção de figos e ao manejo fitossanitário.
Quanto às produções mensais, a colheita no mês de outubro foi praticamente nula (Tabela 3). Em novembro, ocorreram as maiores produções nas plantas podadas em julho e agosto, com média de oito frutos por planta, o que, apesar de ser uma produção baixa para o período, representaria produtividade de $186 \mathrm{~kg} \mathrm{ha}^{-1}$ ao longo do período (em espaçamento $3 \times 2 \mathrm{~m}$, densidade de 1.667 plantas $\left.h^{-1}\right)$. No mês de dezembro, houve aumento significativo nas produções, obtendo-se maiores valores nas plantas podadas entre os meses de junho e agosto (38,75 e 47,50 frutos planta ${ }^{-1}$, respectivamente, em junho e agosto).

Já em janeiro, frente às condições climáticas propícias, concentrou-se o pico de produção de todos os tratamentos, com as maiores produções concentradas nesse mês; não houve diferença estatística entre as épocas de poda, registrando-se mais de 75 frutos por planta, em média, que representa aproximadamente 800 g planta $^{-1}$ e 1.323,55 kg ha-1, no mínimo (Tabela 3). Os bons resultados na colheita mantiveram-se em fevereiro, obtendo-se maior número de frutos por planta em podas realizadas em junho e agosto, mas com produção e produtividade semelhantes à obtida na poda realizada em julho.

Em termos produtivos, as podas realizadas entre os meses de junho e agosto apresentaram escalonamento da produção entre os meses de dezembro e fevereiro. Esse fato é importante economicamente ao ficicultor, uma vez que os doces oriundos de figos-verdes são preferencialmente consumidos no final do ano, por se tratar de um doce tipicamente natalino (Pio et al., 2007).

Santos \& Corrêa (2000) também obtiveram picos na produção de figos-verdes 'Roxo de Valinhos’ entre os meses de janeiro e fevereiro, em plantas podadas em agosto e produzidas em sistema convencional, em Selvíria-MS (temperatura máx. anual de $27^{\circ} \mathrm{C}$ e mín. de $21,4^{\circ} \mathrm{C}$ ), condições essas semelhantes às ocorridas no presente trabalho. Pelo ocorrido em ambos os trabalhos, verifica-se que as maiores produções se concentram no início do verão. Esse resultado é importante para a programação do ficicultor, em se tratando da comercialização dos frutos e no processamento destes.

Quanto aos dados produtivos acumulados na safra de 2007/2008, o maior número de frutos ocorreram em plantas podadas entre os meses de junho e agosto. Mas somente nos meses de julho e agosto constaram-se produções significativas maiores (1.749,9 g e 2.002,06 g, respectivamente), assim como produtividade estimada significamente maiores $\left(2.917,08 \mathrm{~kg} \mathrm{ha}^{-1}\right.$ e $3.337,43 \mathrm{Kg} \mathrm{ha}^{-1}$, respectivamente) (Tabela 3$)$. Vale ressaltar que não 
houve diferença estatística para a massa média dos frutos entre diferentes épocas de poda (Tabela 2), com média aproximada de $10 \mathrm{~g}$ por fruto.

Os resultados apresentados no presente trabalho concordam com os obtidos por Chalfun et al. (1998), que ressaltam que a poda da figueira deve ser realizada no final do período hibernal, entre os meses de julho e agosto. Leonel et al. (2006), trabalhando com diferentes épocas de podas (julho, agosto, setembro e outubro) associadas à irrigação, em Botucatu-SP, obtiveram melhores resultados com a poda realizada no mês de agosto, onde os mesmos verificaram maior número e massa de frutos por planta, além da maior produtividade estimada. Rigitano \& Ojima (1963) estudaram cinco épocas de poda da figueira entre o início de maio e o início de setembro, observando que a poda do início de agosto proporcionou maiores produções nas condições de Campinas-SP.
Norberto et al. (2001), trabalhando com diferentes épocas de poda na produção de figosverdes ‘Roxo de Valinhos' em Lavras, sul do Estado de Minas Gerais, obtiveram produção média de 2.799 g, em plantas podadas no início de agosto, cultivadas em sistema convencional. No presente trabalho, a produção média foi de 2.002,06 g, em plantas podadas no mesmo período, no entanto cultivadas em sistema orgânico. Comparando-se ambos os trabalhos, notase a diferença de 796,94 g de figos entre os dois sistemas de exploração. Mesmo com produções inferiores ao sistema convencional, a agregação de valores obtida com os produtos orgânicos pagos pelos consumidores e ainda o fato de o sistema orgânico possuir custos reduzidos vêm compensar tal diferença na produção de figos-verdes. Além do mais, verificou-se que, além de poder escalonar a colheita, adotando-se épocas de poda distintas, entre os meses de julho e agosto, a produção de figos-verdes em sistema orgânico apresenta bons resultados produtivos.

TABELA 1- Dados referentes à análise de solo realizada na projeção da copa das plantas, antes da instalação do experimento. Análise realizada no Laboratório de Química Agrícola e Instrumental da Unioeste. Marechal Cândido Rondon-PR, Unioeste, 2008.

\begin{tabular}{ccccccccccccccc}
\hline $\mathrm{pH}$ & $\mathrm{MO}$ & $\mathrm{P}$ & $\mathrm{K}$ & $\mathrm{Ca}$ & $\mathrm{Mg}$ & $\mathrm{Al}$ & $\mathrm{H}+\mathrm{Al}$ & $\mathrm{SB}$ & $\mathrm{T})$ & $\mathrm{V}$ & $\mathrm{Cu}$ & $\mathrm{Mn}$ & $\mathrm{Zn}$ & $\mathrm{Fe}$ \\
\hline $\mathrm{CaCl}_{2}$ & $---\mathrm{mg} \mathrm{dm}^{-3}---$ & $----------------------\mathrm{cmol}_{\mathrm{c}} \mathrm{dm}^{-3}--------------------$ & $\%$ & $----------\mathrm{mg} \mathrm{dm}^{-3}-----------$ \\
\hline 6,8 & 47,1 & 126,6 & 0,8 & 9,5 & 2,8 & 0 & 2,4 & 13,2 & 15,6 & 84,1 & 6,0 & 155,0 & 11,4 & 20,1 \\
$* * \mathrm{Mba}$ & - & $\mathrm{A}$ & $\mathrm{Ba}$ & $\mathrm{A}$ & $\mathrm{Ba}$ & $\mathrm{Mba}$ & $\mathrm{Ba}$ & $\mathrm{A}$ & $\mathrm{A}$ & $\mathrm{A}$ & $\mathrm{M}$ & $\mathrm{A}$ & $\mathrm{A}$ & $\mathrm{A}$ \\
\hline
\end{tabular}

${ }^{*} \mathrm{pH}$ em $\mathrm{CaCl}_{2}$; $\mathrm{MO}$ - matéria orgânica; P-K - Extrator Mehlich 1; Ca-Mg-Al - Extrator $\mathrm{KCl}$ 1N; H+Al - Extrator SMP; SB - Soma de Bases Trocáveis; CTC (T) - Capacidade de Troca Catiônica a pH 7,0; V - Índice de Saturação de Bases.

** Mba-muito baixo; Ba-baixo; M-médio; Bo-bom; A-alto - Referente à Recomendação de adubação e calagem de frutas de clima temperado: figo, do Boletim 100 do Instituto Agronômico (Van Raij et al., 1997).

TABELA 2- Número de horas de frio abaixo de $7,2^{\circ} \mathrm{C}$ acumuladas até o momento de cada poda, unidades de graus-dia acumuladas da poda ao final da safra para cada época de poda, variáveis fenológicas (período entre a poda e a desbrota, período entre a desbrota e a primeira colheita e período de safra, em dias), comprimento final médio dos ramos (cm) e massa fresca média (g) de frutos verdes de figueira 'Roxo de Valinhos' (Ficus carica L.), em plantas submetidas a diferentes épocas de poda, conduzidas em sistema orgânico. Marechal Cândido Rondon-PR, Unioeste, 2008.

\begin{tabular}{|c|c|c|c|c|c|c|c|}
\hline \multirow{2}{*}{$\begin{array}{l}\text { Época } \\
\text { de poda }\end{array}$} & \multirow{2}{*}{$\begin{array}{c}\text { Horas de frio } \\
\left(<7,2^{\circ} \mathrm{C}\right) \\
\text { acumuladas até } \\
\text { a poda }\end{array}$} & \multirow{2}{*}{$\begin{array}{c}\text { Graus-dia } \\
\text { acumulados da } \\
\text { poda ao final } \\
\text { da safra }\end{array}$} & \multicolumn{5}{|c|}{ Variáveis fenológicas* } \\
\hline & & & $\begin{array}{c}\text { Desbrota } \\
\text { (dias) }\end{array}$ & $\begin{array}{c}1^{\circ} \text { colheita } \\
\text { (dias) }\end{array}$ & $\begin{array}{c}\text { Período } \\
\text { de safra } \\
\text { (dias) }\end{array}$ & $\begin{array}{l}\text { Comprimento } \\
\text { dos ramos } \\
(\mathrm{cm})\end{array}$ & $\begin{array}{c}\text { Massa } \\
\text { fresca dos } \\
\text { frutos }(g)\end{array}$ \\
\hline Abril & 0 & $5.186,52$ & $37 \mathrm{c}$ & $210 \mathrm{e}$ & $60 \mathrm{~d}$ & $125,62^{\mathrm{ns}}$ & $10,27^{\mathrm{ns}}$ \\
\hline Maio & 0 & $4.666,21$ & $100 \mathrm{f}$ & $90 \mathrm{~d}$ & $60 \mathrm{~d}$ & 129,14 & 10,19 \\
\hline Junho & 40,2 & $4.386,62$ & 88 e & $50 \mathrm{~b}$ & $100 \mathrm{~b}$ & 130,77 & 9,86 \\
\hline Julho & 60,5 & $4.094,80$ & $70 \mathrm{~d}$ & $40 \mathrm{a}$ & $110 \mathrm{a}$ & 128,13 & 10,74 \\
\hline Agosto & 126,0 & $3.870,89$ & $30 \mathrm{~b}$ & $40 \mathrm{a}$ & $110 \mathrm{a}$ & 128,43 & 10,77 \\
\hline Setembro & 135,1 & $3.563,21$ & $25 \mathrm{a}$ & $60 \mathrm{c}$ & $80 \mathrm{c}$ & 120,62 & 10,11 \\
\hline C.V. $(\%)$ & - & - & 1,38 & 1,12 & 2,71 & 7,05 & 5,89 \\
\hline
\end{tabular}

* Médias seguidas pela mesma letra em minúsculo na coluna não diferem entre si, pelo teste Scott-Knott $(\mathrm{P} \leq 0,05)$. 
TABELA 3- Produção (número médio de frutos por planta e massa de frutos acumulada por planta) e produtividade estimada (espaçamento de $3 \mathrm{~m}$ x $2 \mathrm{~m}$, densidade de 1.667 plantas ha-1 $^{-1}$ ) de frutos verdes de figueira 'Roxo de Valinhos' (Ficus carica L.), por mês, e acumulada na safra, em plantas submetidas a diferentes épocas de poda, conduzidas em sistema orgânico. Marechal Cândido Rondon-PR, Unioeste, 2008.

\begin{tabular}{|c|c|c|c|c|c|c|c|c|}
\hline \multirow[t]{2}{*}{ Época de poda } & \multicolumn{2}{|c|}{ Out. } & \multicolumn{2}{|c|}{ Nov. } & Dez. & Jan. & \multirow[t]{2}{*}{ Fev. } & \multirow{2}{*}{$\begin{array}{c}\text { Produção } \\
\text { acumulada safra }\end{array}$} \\
\hline & \multicolumn{6}{|c|}{ Produção (frutos planta $\left.{ }^{-1}\right)^{*}$} & & \\
\hline Abril & 0 & $\mathrm{Da}$ & $0,7 \quad \mathrm{D}$ & & $18,85 \mathrm{Cb}$ & 75,32 Aa & $43,92 \mathrm{Ba}$ & $138,16 \mathrm{~b}$ \\
\hline Maio & 0 & $\mathrm{Ca}$ & 0 & & $25,65 \mathrm{Bb}$ & $81,80 \mathrm{Aa}$ & $15,67 \mathrm{Bc}$ & $123,17 \mathrm{~b}$ \\
\hline Junho & 0 & $\mathrm{Da}$ & $2,67 \mathrm{Cl}$ & & $38,75 \mathrm{Ba}$ & $78,65 \mathrm{Aa}$ & $41,32 \mathrm{Ba}$ & $161,41 \mathrm{a}$ \\
\hline Julho & 0,67 & $\mathrm{Ca}$ & $8,85 \mathrm{Ca}$ & & $43,82 \mathrm{Ba}$ & 79,57 Аa & $29,25 \mathrm{Bb}$ & 162,16 a \\
\hline Agosto & 0,42 & $\mathrm{Da}$ & $8,85 \mathrm{Ca}$ & & $47,50 \mathrm{Ba}$ & 84,75 Aa & $42,75 \mathrm{Ba}$ & 184,25 a \\
\hline Setembro & 0 & $\mathrm{Ca}$ & 0 & & $28,40 \mathrm{Bb}$ & $94,00 \mathrm{Aa}$ & $27,96 \mathrm{Bb}$ & $145,22 \mathrm{~b}$ \\
\hline C.V. (\%) mês & & & & & 25,84 & & & \\
\hline \multirow[t]{2}{*}{ C.V. $(\%)$ época } & & & & & 18,28 & & & 12,65 \\
\hline & \multicolumn{8}{|c|}{ Produção $\left(\text { g planta }^{-1}\right)^{*}$} \\
\hline Abril & 0 & $\mathrm{Da}$ & 0,80 & Dc & $182,77 \mathrm{Cb}$ & $793,95 \mathrm{Aa}$ & $441,85 \mathrm{Ba}$ & $1.419,40 \mathrm{~b}$ \\
\hline Maio & 0 & $\mathrm{Ca}$ & 0 & $\mathrm{Cc}$ & $237,25 \mathrm{Bb}$ & 860,77 Aa & $158,37 \mathrm{Bb}$ & $1.256,41 \mathrm{~b}$ \\
\hline Junho & 0 & $\mathrm{Da}$ & 32,55 & $\mathrm{Cb}$ & $394,42 \mathrm{Ba}$ & $844,12 \mathrm{Aa}$ & $322,27 \mathrm{Ba}$ & $1.593,40 \mathrm{~b}$ \\
\hline Julho & 5,62 & $\mathrm{Ea}$ & 111,75 & $\mathrm{Da}$ & $485,00 \mathrm{Ba}$ & $857,97 \mathrm{Aa}$ & $289,60 \mathrm{Ca}$ & $1.749,90 \mathrm{a}$ \\
\hline Agosto & 4,35 & $\mathrm{Da}$ & 112,35 & $\mathrm{Ca}$ & $520,87 \mathrm{Ba}$ & $943,80 \mathrm{Aa}$ & $420,65 \mathrm{Ba}$ & $2.002,06 \mathrm{a}$ \\
\hline Setembro & 0 & $\mathrm{Ca}$ & 0 & $\mathrm{Cc}$ & $269,57 \mathrm{Bb}$ & $976,87 \mathrm{Aa}$ & $285,80 \mathrm{Bb}$ & $1.469,00 \mathrm{~b}$ \\
\hline C.V. (\%) mês & & & & & 24,31 & & & \\
\hline \multirow[t]{2}{*}{ C.V. $(\%)$ época } & & & & & 19,29 & & & 17,04 \\
\hline & \multicolumn{8}{|c|}{ Produtividade $\left(\mathrm{Kg} \mathrm{ha}^{-1}\right)^{*}$} \\
\hline Abril & 0 & $\mathrm{Da}$ & 1,35 & Dc & $304,67 \mathrm{Cb}$ & $1323,55 \mathrm{Aa}$ & $736,60 \mathrm{Ba}$ & $2.366,15 \mathrm{~b}$ \\
\hline Maio & 0 & $\mathrm{Ca}$ & 0 & $\mathrm{Cc}$ & $395,52 \mathrm{Bb}$ & $1434,92 \mathrm{Aa}$ & $264,02 \mathrm{Bb}$ & $2.094,44 \mathrm{~b}$ \\
\hline Junho & 0 & $\mathrm{Da}$ & 54,27 & $\mathrm{Cb}$ & $657,50 \mathrm{Ba}$ & $1407,20 \mathrm{Aa}$ & $537,22 \mathrm{Ba}$ & $2.656,20 \mathrm{~b}$ \\
\hline Julho & 9,35 & $\mathrm{Ea}$ & 186,27 & $\mathrm{Da}$ & $808,52 \mathrm{Ba}$ & $1430,25 \mathrm{Aa}$ & $482,72 \mathrm{Ca}$ & $2.917,08 \mathrm{a}$ \\
\hline Agosto & 7,22 & $\mathrm{Da}$ & 187,30 & $\mathrm{Ca}$ & $868,32 \mathrm{Ba}$ & $1573,35 \mathrm{Aa}$ & $701,25 \mathrm{Ba}$ & $3.337,43$ a \\
\hline Setembro & 0 & $\mathrm{Ca}$ & 0 & $\mathrm{Cc}$ & $449,37 \mathrm{Bb}$ & $1628,45 \mathrm{Aa}$ & $476,43 \mathrm{Bb}$ & $2.448,82 \mathrm{~b}$ \\
\hline C.V. (\%) mês & & & & & 24,31 & & & \\
\hline C.V. $(\%)$ época & & & & & 19,39 & & & 17,04 \\
\hline
\end{tabular}

* Médias seguidas pela mesma letra em maiúsculo na linha e minúsculo na coluna não diferem entre si, pelo teste ScottKnott $(\mathrm{P} \leq 0,05)$.

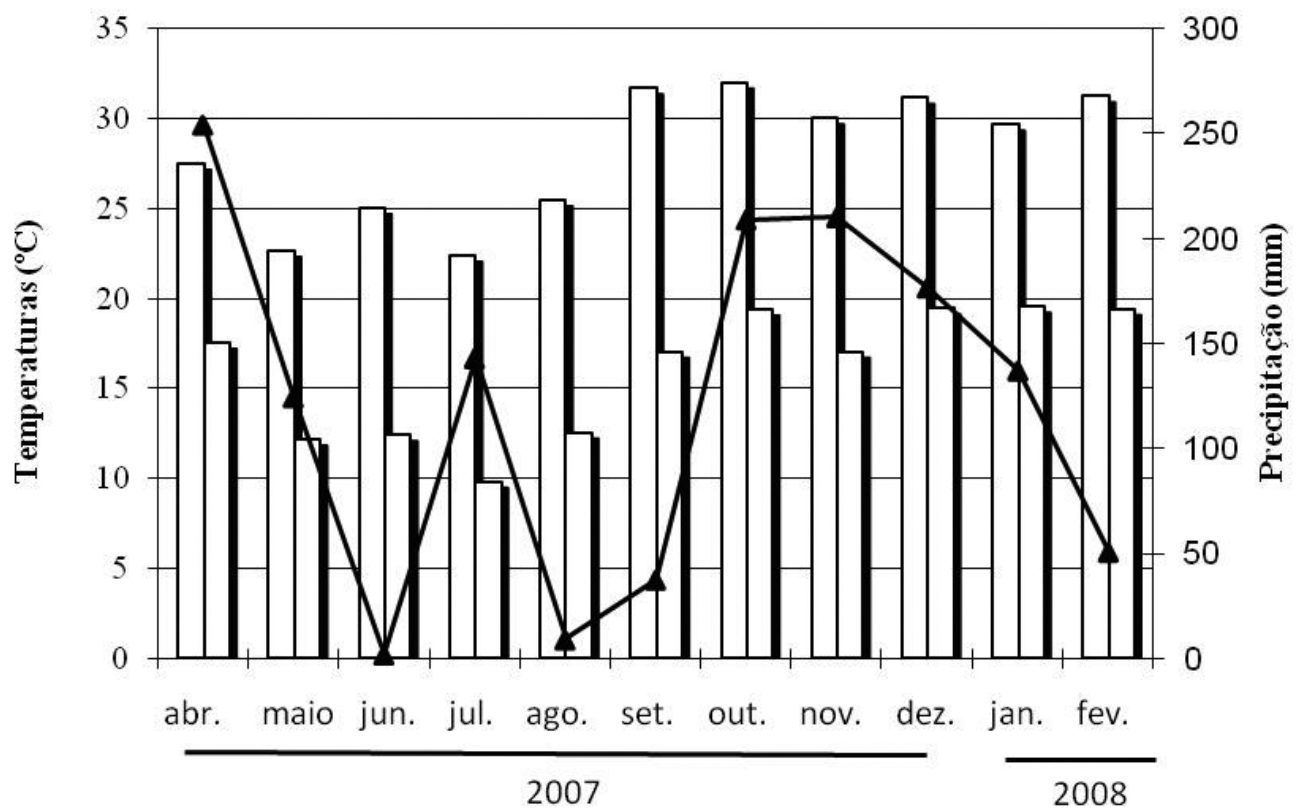

FIGURA 1 - Temperaturas médias máximas e mínimas e precipitação acumulada para os meses de abril de 2007 a fevereiro de 2008. Marechal Cândido Rondon-PR, Unioeste, 2008. 


\section{CONCLUSÃO}

Baseado nos resultados obtidos, comprovase a eficiência produtiva de figos-verdes em sistema orgânico. Plantas podadas em julho e agosto, com acúmulo de graus-dia entre 4.094,80 e 3.870,89, apresentaram as maiores produções, com colheita escalonada entre os meses de dezembro e fevereiro, e pico de produção em janeiro.

\section{REFERÊNCIAS}

AGRIANUAL 2007: anuário estatístico da agricultura brasileira. São Paulo: FNP. Consultoria e Comércio, 2007.536p.

ALVARENGA, A.A.; ABRAHAO, E.; FRAGUAS, J.C.; CARVALHO, V.L.; SILVA, R.A.; SANTA CECILIA, L.V.C.; CUNHA, R.L.; SILVA, V.J. Figo (Ficus carica L.). In: TRAZILBO JR, J.P. MADELAINE V. (Org.). 101 culturas: manual de tecnologias agrícolas. Belo Horizonte: EPAMIG, 2007. p.365-372.

CHALFUN, N.N.J.; ABRAHÃO, E.; ALVARENGA, A.A.; REGINA, M.A.; PIO, R. Poda e condução da figueira. Lavras: UFLA, 2002. 12p. (Boletim Técnico, 104).

CHALFUN, N.N.J.; PASQUAL, M.; HOFFMANN, A. Fruticultura comercial: frutíferas de clima temperado. Lavras: UFLA/FAEPE, 1998. 304 p.

EMBRAPA. Centro Nacional de Pesquisa de Solos. Sistema brasileiro de classificação de solos. 2. ed. Rio de Janeiro: EMBRAPA/SOLOS, 2006. 306p.

FAO - Food And Agriculture Organization. Fig. Disponível em: <http://faostat.fao.org > Acesso em: 15 abr 2008.

FRANCISCO, V.L.F.S.; BAPTISTELLA, C.S.L.; SILVA, P.R. A cultura do figo em São Paulo. Disponível em: <http://www.iea.sp.gov.br>. Acesso em: 15 abr 2008.
IBGE - Instituto Brasileiro de Geografia e Estatística. Produção agrícola municipal. Disponível em: <http:/ /www.ibge.gov.br>. Acesso em: 15 abr 2008.

LEONEL, S.; TECCHIO, M.A.; DUARTE FILHO, J. Épocas de poda e irrigação complementar na cultura da figueira. In: CONGRESSO BRASILEIRO DE FRUTICULTURA, 19., 2006, Cabo Frio. Anais... Cabo Frio: SBF, 2006. CD-ROM.

MAACK, R. Geografia física do Estado do Paraná. 2. ed. Rio de Janeiro: J. Olympio, 1981. 450p.

NORBERTO, P.M.; CHALFUN, N.N.J.; PASQUAL, M.; VEIGA, R.D.; MOTA, J.H. Efeito de época de poda, cianamida hidrogenada e irrigação na produção antecipada de figos-verdes. Pesquisa Agropecuária Brasileira, Brasília, v.36, n.11, p.1363-1369, 2001.

PEDRO JÚNIOR, M.J.; ORTOLANI, A.A.; RIGITANO, O.; ALFONSI, R.R.; PINTO, H.S.; BRUNINI, O. Estimativa de horas de frio abaixo de 7 e $13^{\circ} \mathrm{C}$ para a regionalização da fruticultura de clima temperado no Estado de São Paulo. Bragantia, Campinas, v.38, n.13, p.123-130, 1979.

PIO, R.; CHAGAS, E.A.; CAMPO DALL'ORTO, F.A.; BARBOSA, W. Manejo para o cultivo da figueira. Campo \& Negócio, Uberlândia, p.62 - 63, 2007.

RIGITANO, O.; OJIMA, M. Épocas de poda da figueira cultivada no Estado de São Paulo. Bragantia, Campinas, v.22, n.42, p.529-536, 1963.

SANTOS, S.C.; CORRÊA, L.S. Desenvolvimento e produção da figueira (Ficus carica L.) cultivada em Selvíria-MS. Revista Brasileira de Fruticultura, Jaboticabal, v.22, n.2, p.213-217, 2000.

VAN RAIJ, B.; CANTARELLA, H.; QUAGGIO, J.A.; FURLANI, A.M.C. Recomendações de adubação e calagem para o Estado de São Paulo. 2.ed. Campinas: Instituto Agronômico/Fundação IAC, 1997. 285p.

VILLA NOVA, N.A.; PEDRO JÚNIOR, M.J.; PEREIRA, A.R.; OMETTO, J.C. Estimativa de grausdia acumulados acima de qualquer temperatura base, em função das temperaturas máxima e mínima. São Paulo: USP, 1972. 7 p. (Caderno de Ciências da Terra, 30). 